\title{
The Design of Solar Bike
}

\section{Xiao-Yun Li ${ }^{1}$, Yi-Jui Chiu ${ }^{1, a^{*}}$, Ke-Ke Sun ${ }^{2, b}$, Sheng-Bo Li ${ }^{1, \mathrm{c}}$ and Da Su${ }^{1}$}

${ }^{1}$ School of Mechanical and Automotive Engineering, Xiamen University of Technology, No. 600, Ligong Rd, Xiamen, 361024, Fujian Province, China.

${ }^{2}$ School of Design Arts and Fashion Design, Xiamen University of Technology, No. 600, Ligong Rd, Xiamen, 361024, Fujian Province,China.

a*chiuyijui@xmut.edu.cn, bsunkeke@xmut.edu.cn, chit4057@xmut.edu.cn

* The corresponding author

Keywords: Solar Energy; Electric Bicycle; Static Analysis; Modal Analysis

\begin{abstract}
This paper used solidworks to design solar powered electric bike structure. By comparing and verifying the possibility of several installation methods, the program determined that the solar panels is placed in front and rear frame and that the solar tracking device is installed. And the structure interfaced into the ANSYS through the graphical data conversion. The finite element model of the bike is generated by grid division. The finite element analysis of the solar panel installation location is carried out. The strength and stiffness characteristics of the vehicle body are calculated in the static analysis. The frequency of the vehicle body is calculated by modal analysis.
\end{abstract}

\section{Introduction}

The new structure of solar electric bicycle is designed by authors as shows in Fig. 1, including Handlebar, Main frame, Solar panel and Wheels.

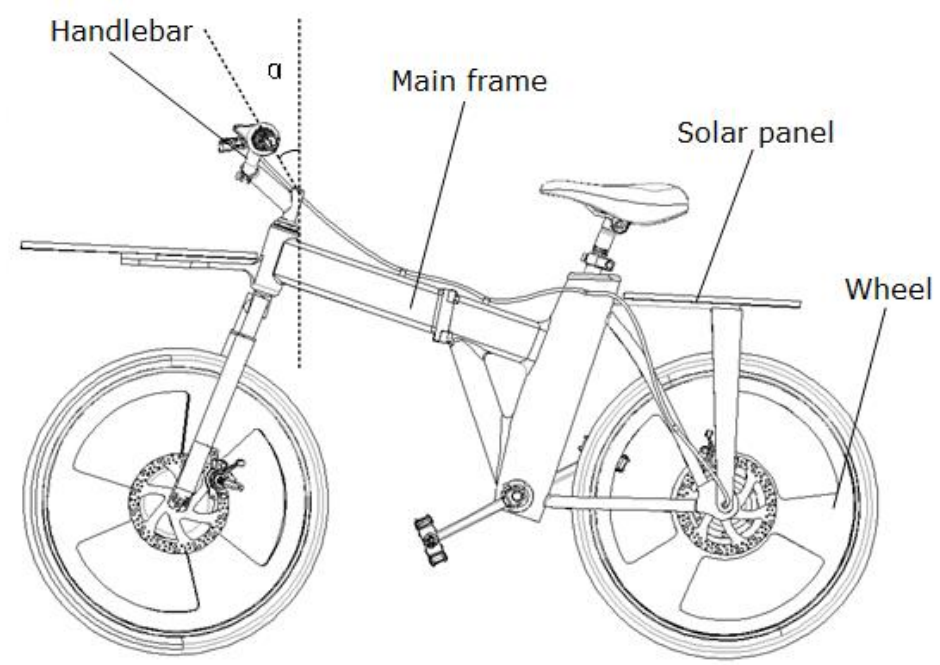

Figure 1. The model of solar electric bicycle

The solar bike will be demand of near future. It will save the non-renewable resources and make environment clean and green. The researches are in this field, such as Parmar et. al. [1] designed the solar bike by selecting the power and battery. After assembling solar panel and power transmission system, determine the discharge time of the battery under different conditions. Beedu et. al. [2] discussed the relationship between speed and power of bicycle. The experiments are done on plain flat road, plain road with a slope of $15 \mathrm{o}$ and $30 \mathrm{o}$ at a maximum speed of $15 \mathrm{Km} / \mathrm{h}$. The bike can easily climb a slope of 30o. Chouhary et. al. [3] adopted the experimental method to design the solar bike by devising motor controller and solar panel. Li et. al. [4] designed a solar electric bicycle hybrid power supply controller. The power output and speed of electric bicycle will increase putting the converters in 
parallel. Lv et. al. [5] devised the solar battery charging control system to achieve maximum power point tracking. The results show that the design has high tracking efficiency. Liu et. al. [6] analyze the efficiency and performance of the solar power system by maximum power tracking method. They design the charging system with the DC/DC converter.

The intention of this paper is to design the structure of solar bicycle by selecting motor and transmission chain. On the basis of meeting stiffness, strength requirements and the feasibility analysis of several programs, the final program is determined, and vibration analysis is performed.

\section{Theories Analysis}

The safety factor method is used to determine whether the stress meets the strength requirements in this paper. Whether the maximum stress is taken by the electric bicycle or whether it is within the allowable stress range of the material. In static analysis, the allowable stress of electric bicycles is

$$
[\sigma]=\frac{\sigma_{b}}{n}
$$

where $\sigma_{b}$ is the ultimate strength, $\mathrm{n}$ is the safety factor.

The modal analysis of the frame is carried out in the case of unconstrained. When the solar electric bike travels on the road, the input time frequency is:

$$
f=v \Omega
$$

where $\mathrm{v}$ is the speed of bicycle, $\Omega$ is the spatial frequency of pavement roughness. When the bike resonates, the speed of bicycle is:

$$
v=3.6 L_{w} f(\mathrm{~km} / \mathrm{h})
$$

where $L_{w}$ is the wavelength of pavement roughness, $\mathrm{f}$ is the input time frequency.

Because the structure of solar powered electric bike was complex, we should simplify the structure first. This paper exports the equations of the system.

$$
[M]\{\ddot{X}\}+[K]\{X\}=0
$$

Defined the position vector $\{\mathrm{X}\}$ as $[\Delta]\{\mathrm{u}\}$, where $[\Delta]$ was the modal matrix of the system. Eq. (4) could be changed as follow:

$$
[I]\{\ddot{u}\}+[A]\{u\}=0
$$

In which:

$$
\begin{gathered}
{[\Delta]^{T}[M][\Delta]=[\boldsymbol{I}]=\left[\begin{array}{cccc}
1 & 0 & \cdots & 0 \\
0 & 1 & \cdots & \vdots \\
\vdots & 0 & \ddots & 0 \\
0 & 0 & 0 & 1
\end{array}\right]} \\
{[\Delta]^{T}[K][\Delta]=[A]=\left[\begin{array}{cccc}
{\overline{\omega_{1}}}^{2} & 0 & \cdots & 0 \\
0 & \bar{\omega}_{2}^{2} & \cdots & \vdots \\
\vdots & 0 & \ddots & 0 \\
0 & \cdots & 0 & \frac{\omega}{n}^{2}
\end{array}\right]}
\end{gathered}
$$

The natural frequency of the mistuned system was expressed as follow:

$$
\overline{\omega_{n}}=\frac{\omega_{n}}{\sqrt{\frac{E I}{\rho A L^{4}}}}, n=1,2,3 \ldots . .
$$




\section{Finite Element Modeling}

This paper imported the 3D geometry model built in SolidWorks into ANSYS, as shown in Fig. 2. The aluminum alloy is taken as the material for the frame structure, and the specific parameters are shown in the following Table 1. After the mesh is divided, the finite element model is shown in Fig. 3. Set the physical field to mechanical. The overall grid uses the default meshing settings. And Refinement is used in the installation location to refine the grid. Before the simulation analysis, we need to check the grid quality. The model contains 80979 elements and 143266 nodes. The element types are choice 3D hexahedral solid elements.

Table 1. Car body material parameter

\begin{tabular}{ccccc}
\hline & Density & $\begin{array}{c}\text { Young } \\
\text { Modulus }\end{array}$ & $\begin{array}{c}\text { Shear } \\
\text { Modulus }\end{array}$ & Poisson ratio \\
\hline Aluminium & $2.77 \mathrm{~g} / \mathrm{cm}^{3}$ & $7.1 \times 1010 \mathrm{~Pa}$ & $2.67 \times 1010 \mathrm{~Pa}$ & 0.33 \\
\hline
\end{tabular}

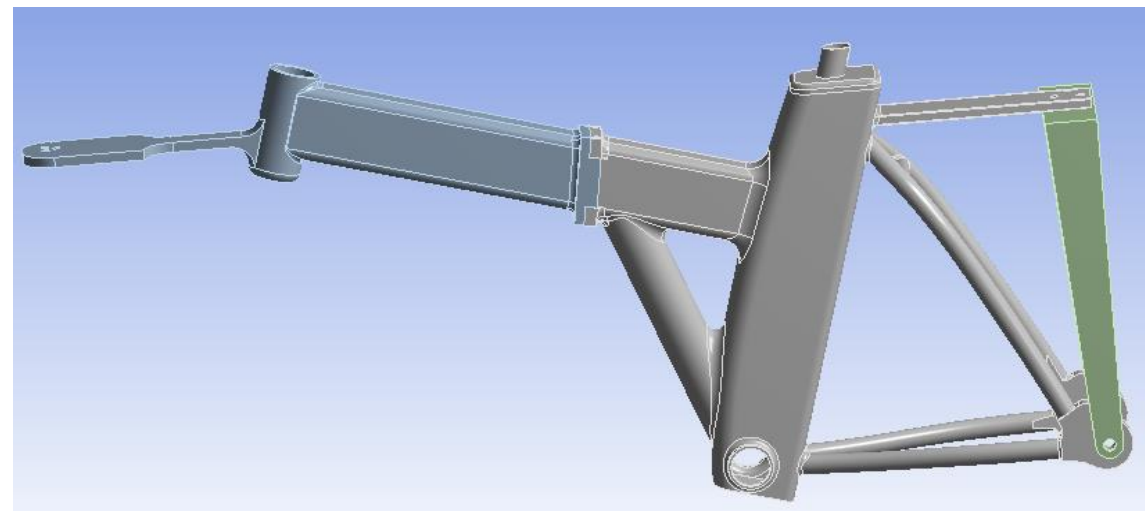

Figure 2. Model import

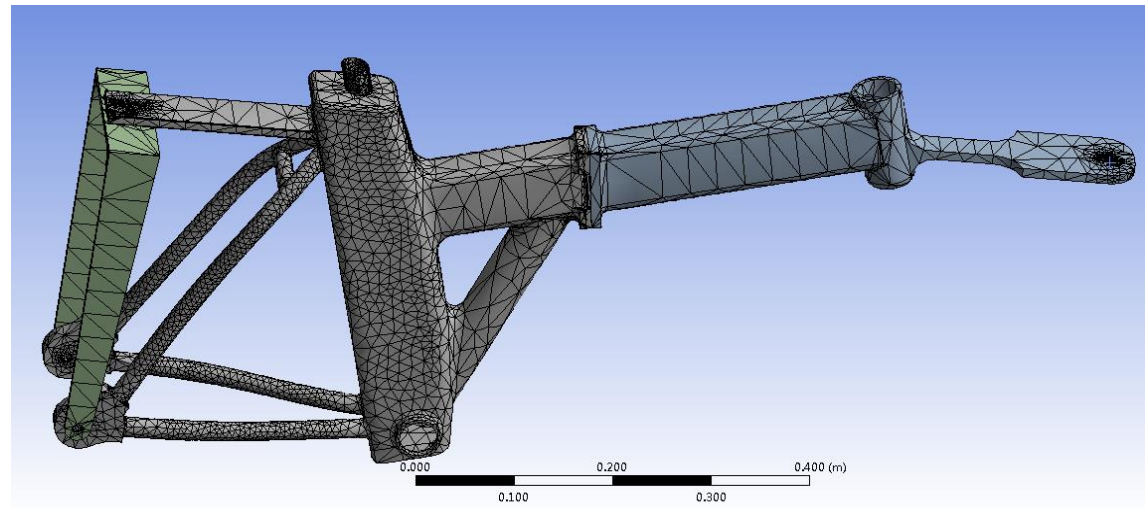

Figure 3. Mesh divides

There are a few indexes related to grid quality. In which, Element Quality is the ratio between the volume of a unit and the length of the side. Aspect Ratio is the ratio of the horizontal dimension to the longitudinal dimension. The bigger value isn't better. Jacobian Ratio is the ratio of the maximum and the minimum. The larger value illustrates that the unit is more twisted. Skewness is Unit Distortion. Orthogonal Quality, the greater the value is, the better the result gets. When the Warping Factor and Parallel Deviation values are both 0 , the result is the best.

\section{Static Analysis}

Loading mode of bike frame is shown in Fig.4. The boundary condition is the degree of freedom of frame to restrain the $\mathrm{X}, \mathrm{Y}$ and $\mathrm{Z}$ directions before and after the constraint. The static load on the frame is the load caused by the sum of the weight of the frame itself, the solar panel, the motor, the battery, and 
the weight of the person. They act on the corresponding parts of the frame in the form of concentrated loads or distributed loads. The weight of the frame itself is $300 \mathrm{~N}$. Each solar panel weighs $10 \mathrm{~N}$. The motor is $30 \mathrm{~N}$ and the battery is $40 \mathrm{~N}$. The load is given $750 \mathrm{~N}$ concentrated force on the center of the seat. It is also the weight of person.

According to the calculation results of the deformation diagram, folding, three links, after the fork, the next tube, the front plate have more obvious stress. And the maximum stress appears in the fork after the fork. But there is no obvious stress concentration and the force is more uniform. The maximum stress value of the frame is $27.84 \mathrm{Mpa}$. The result is lower than the yield strength of aluminum alloy, and meets the requirements of strength.

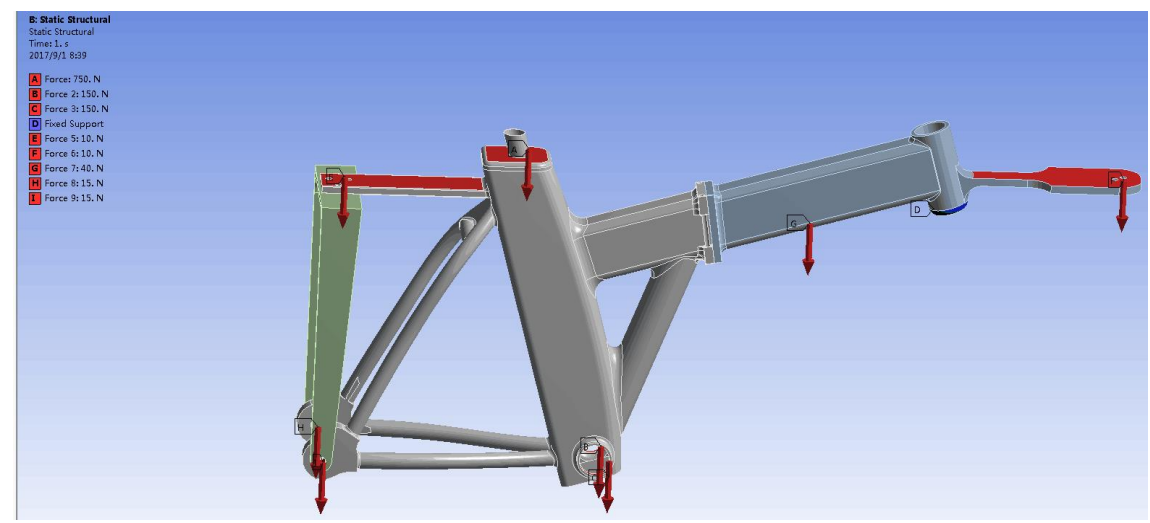

Figure 4. Loading mode of bike frame

By solving the ANSYS processor, the deformation and the stress distribution of the frame can be obtained, as shown in Fig. 5 and Fig. 6.

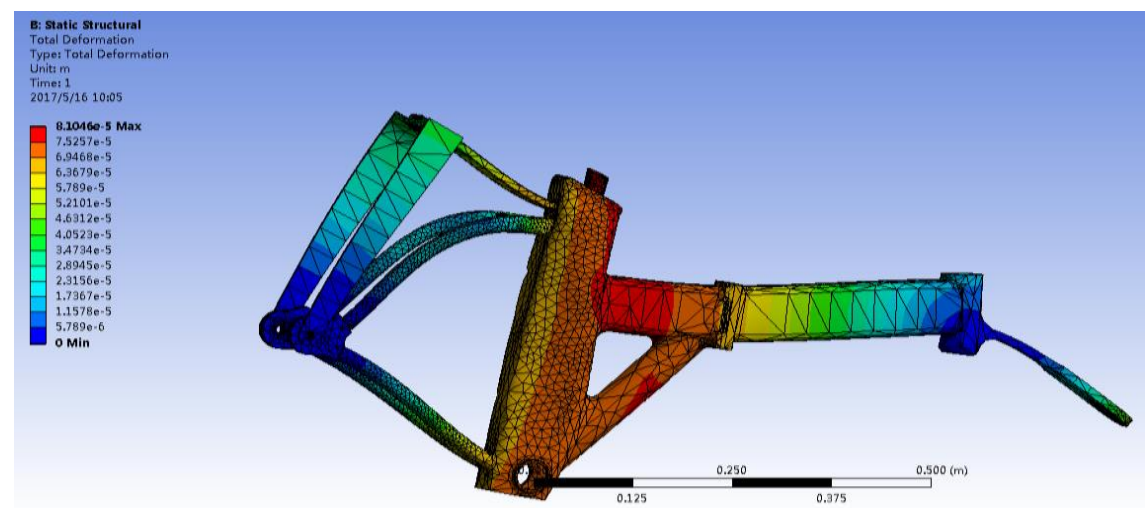

Figure 5. the deformation of the frame

According to the calculation results of the deformation diagram, the maximum deformation occurs in the middle of the frame and is $0.083 \mathrm{~mm}$. This is because the weight of a person exerts a larger load.

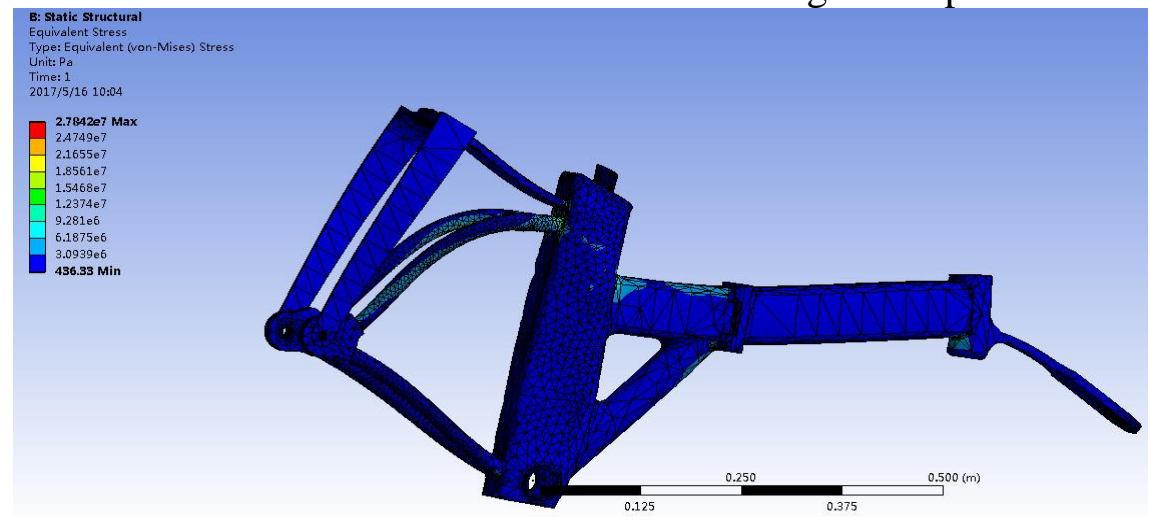

Figure 6. the stress distribution of the frame 
In summary, the design of electric bicycles meets the bike body strength and stiffness requirements. It guarantees the safety and reliability of pure solar bicycles.

\section{Modal Analysis}

The paper simulates the free mode of the frame. The frame is subjected to modal analysis without constraints, and the first six order modes are almost zero, called rigid modes. It does not have much impact on the dynamic load analysis of electric bicycles. Since the excitation of the frame resonance is mainly lower frequency and the total vibration of the structure is superimposed by the frequency of each order, so the lower order mode is more affected. Here we extract the seventh order mode to the twelfth order mode.

Table 2 lists that the frequencies and mode of the bicycle frame. Fig. 7 are the seventh order mode to the twelfth order mode of frame.

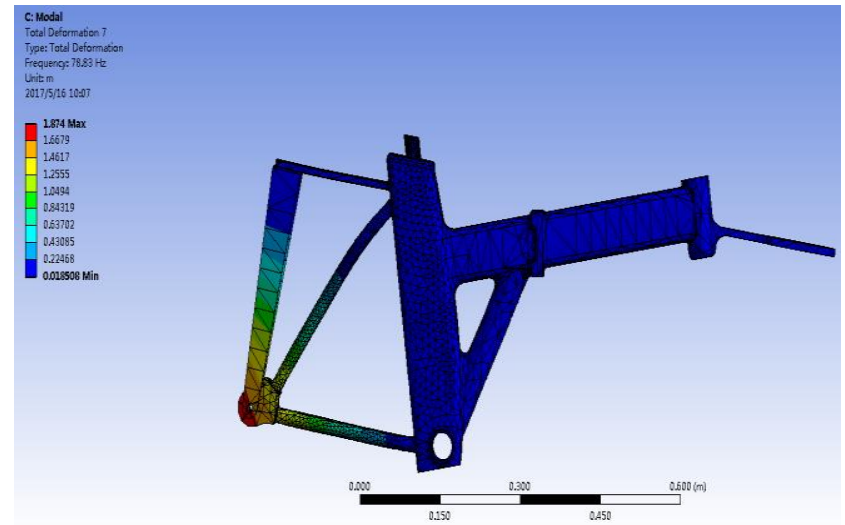

(a) Seventh order mode diagram

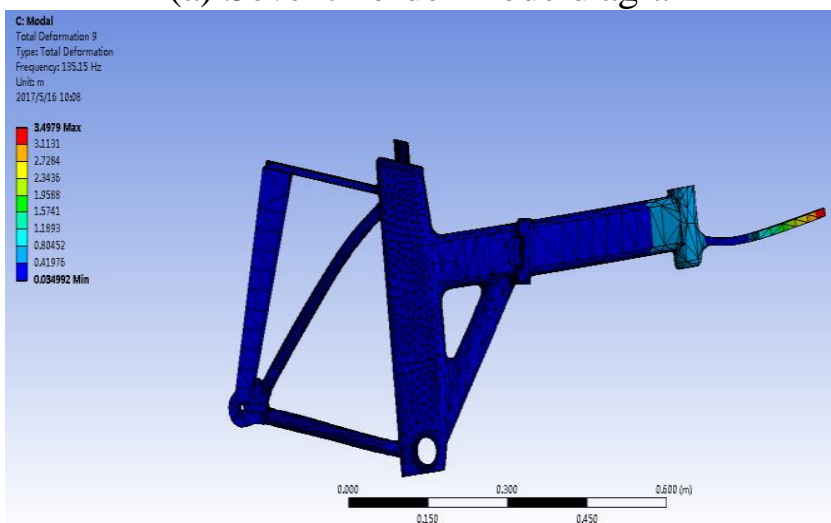

(c) Ninth order mode diagram

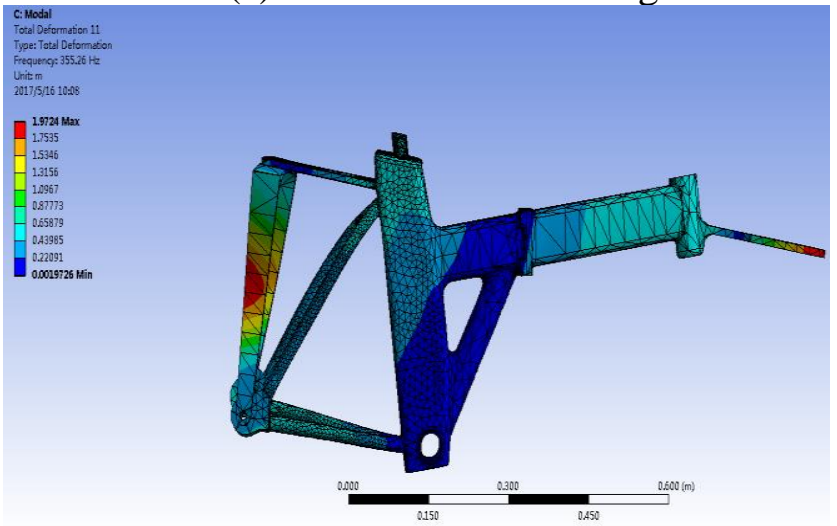

(e) Eleventh order mode diagram

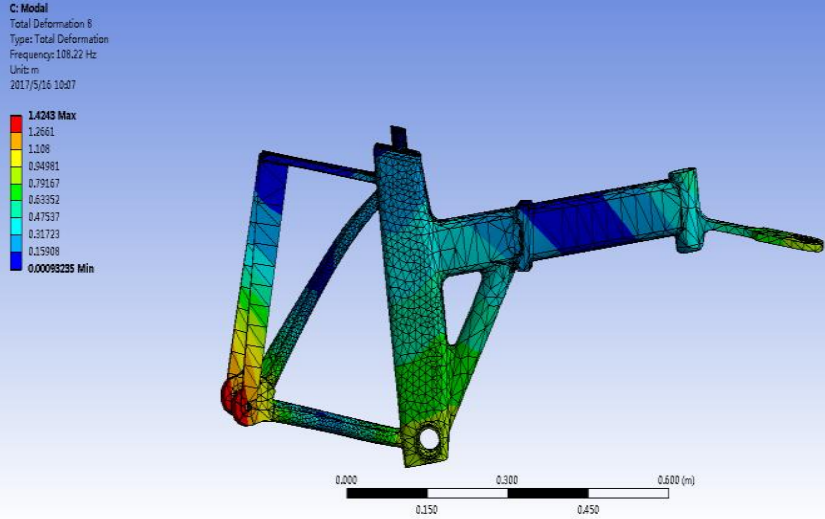

(b) Eighth order mode diagram

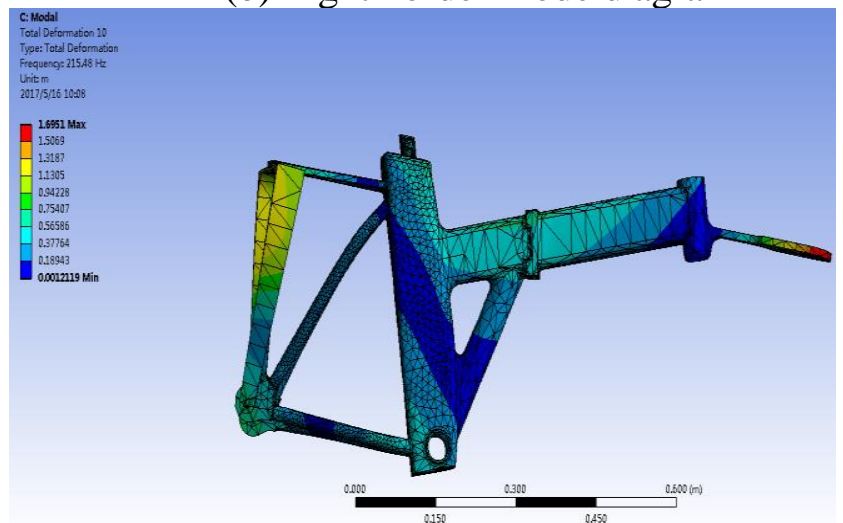

(d) Tenth order mode diagram

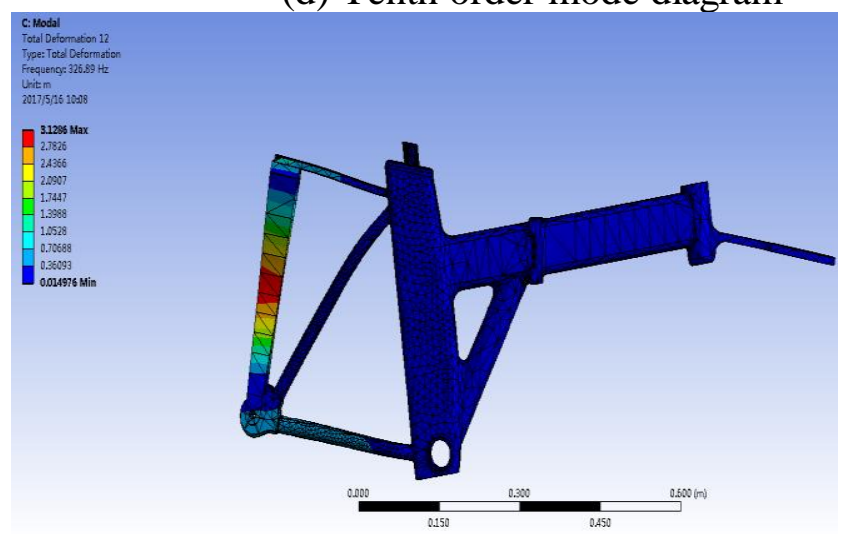

(f) Twelfth order mode diagram

Figure 7. The seventh order mode to the twelfth order mode of frame 
Based on the above modes, it can be found that the front plate and the rear support plate are the regions where resonance deformation is most likely to occur. This is also the location of the installation of solar panels. If a resonance occurs, it will cause the connector to fail and destroy the solar panel structure. The average speed of solar electric bicycles is $20 \sim 30 \mathrm{~km} / \mathrm{h}$, so the natural frequency of the structure should be: $17.36 \sim 26.04 \mathrm{HZ}$. Since the seventh modal frequency of the frame is $78.83 \mathrm{~Hz}$, the excitation of pavement roughness is less likely to cause resonance. Although the installation of solar panels is the most serious resonance location, the stability of the bicycle can be guaranteed under the normal driving conditions.

Table 2 The frequencies and mode of the bicycle frame

\begin{tabular}{ccccc}
\hline Mode & $\begin{array}{c}\text { Frequency } \\
{[\mathrm{Hz}]}\end{array}$ & $\begin{array}{c}\text { Max } \\
\text { deformation }[\mathrm{mm}]\end{array}$ & Vibration type & $\begin{array}{c}\text { Maximum deformation } \\
\text { position }\end{array}$ \\
\hline 7 & 78.83 & 1.874 & $\begin{array}{c}\text { Bend in the longitudinal } \\
\text { direction of the } \mathrm{Y} \text { axis }\end{array}$ & After the fork \\
\hline 8 & 108.22 & 1.4243 & $\begin{array}{c}\text { Bend in the longitudinal } \\
\text { direction of the } \mathrm{Z} \text { axis }\end{array}$ & $\begin{array}{c}\text { The connection of rear } \\
\text { fork and wheel }\end{array}$ \\
\hline 9 & 135.15 & 3.4979 & $\begin{array}{c}\text { Bend laterally along the } \mathrm{Y} \\
\text { axis }\end{array}$ & Front plate \\
\hline 10 & 215.48 & 1.6951 & $\begin{array}{c}\text { Bend laterally along the } \\
\text { Z axis }\end{array}$ & $\begin{array}{c}\text { Front plate and rear } \\
\text { support plate }\end{array}$ \\
\hline 12 & 355.26 & 1.9724 & Bend along the $\mathrm{Y}$ axis & Rear support plate \\
\hline 326.89 & 3.1286 & Bend along the Z axis & $\begin{array}{c}\text { Front plate and rear } \\
\text { support plate }\end{array}$ \\
\hline
\end{tabular}

In fact, during the process of driving, the vibration of the bicycle will be affected by various factors, such as bad road conditions, gravel impact and so on. It will produce high-frequency pulse excitation and may cause high-order frequency resonance. So we need to give the appropriate shock under the actual road conditions to detect the stability of solar panels.

\section{Conclusion}

Traditional solar cells have high cost and low conversion efficiency. This article provides a solar portable bike. The author used the finite element analysis method of mechanics based on ANSYS software. The bicycle frame design and modal analysis is carried out to ensure the structural mechanical characteristics of the solar bike.

\section{Acknowledgements}

This study is sustained by Fujian Nature Project No. 2016J01039 and 2015J01228, Xiamen City Project No. $3502 Z 20173037$

\section{References}

[1] Parmar M., Trivedi R., Nair S. and Vora V., (2016), Solar powered E-Bike. Imperial Journal of Interdisciplinary Research. 5, pp. 1535-1537.

[2] Beedu R., Ankit, Shalk M.A. and Jain S., (2014), Design, fabrication and performance analysis of solar power bicycle. International Journal of Renewable Energy and Environmental Engineering. 03, pp. 190-192.Talpur

[3] Chouhary E.M.B., Talpur E.S.,Zafar E.T., Hussain E.M. and Raza E.A., (2016), Solar powered electric bike. European International Journal of Science and Technology. 5. pp. 77-82. 
[4] Li X.L., Wang D.P., Li J. and Ren M.Q., (2016), Research on Electric Bicycle Power Supply by Solar Energy. ACTA Energiae Solaris Sinica. 37, pp. 884-890.

[5] Lv Y., Deng C.J. and Zou K., (2017), Design and Realization of Solar Charging Device for Low Speed Electric Vehicle. Modern Electronics Technique. 40, pp. 176-179.

[6] Liu M.S., Ma Y., Li C. and Liu Y.C., (2014), Research on power management system based on solar electric bicycle. Science \& Technology Vision. 36, pp. 11-12. 